\title{
DAMPAK PEMBERLAKUAN CLINICAL PATHWAY TERHADAP KUALITAS PELAYANAN STROKE DI RS BETHESDA YOGYAKARTA
}

\author{
Tiara Kusumaningtyas ${ }^{1}$, Adi Utarini ${ }^{1}$, Rizaldy Taslim Pinzon ${ }^{2}$ \\ ${ }^{1}$ Bagian Ilmu Kesehatan Masyarakat Fakultas Kedokteran Universitas Gadjah \\ Mada \\ ${ }^{2}$ Fakultas Kedokteran Universitas Kristen Duta Wacana \\ Korespondensi: tiara_blue_2@yahoo.com
}

\begin{abstract}
ABSTRAK
Latar belakang: Stroke masih menjadi masalah kesehatan dunia. Dibutuhkan solusi manajemen klinis yang lebih baik guna mengupayakan pelayanan stroke yang berkualitas. Sebagai sebuah instrumen yang menstandarisasi proses dan outcome pelayanan, clinical pathway selayaknya mampu menjadi solusi perbaikan manajemen kualitas berkelanjutan. Hingga kini bukti mengenai efektivitas clinical pathway masih diperdebatkan.

Tujuan: Untuk mengevaluasi dampak clinical pathway terhadap perbaikan kualitas pelayanan stroke berdasarkan indikator proses dan outcome.

Metode: Metode yang digunakan dalam penelitian ini adalah metode before-after without control group quasi exsperimental, dimana dilakukan penilaian pre dan post implementasi pada dua kelompok tanpa randomisasi. Kelompok intervensi adalah kelompok subyek yang ditatalaksana dengan clinical pathway sedangkan kelompok kontrol adalah kelompok pasien sebelum pemberlakuan pathway (diambil dari data sekunder rekam medis). Outcome mortalitas sebagai output primer dari penelitian ini akan dibandingkan antara kelompok kontrol dan kelompok intervensi.

Hasil: Karakteristik subyek dalam penelitian ini homogeny dalam hal variabel demografi (kecuali jenis kelamin) dan karakteristik klinis gejala wajah perot, faktor risiko dan komorbiditas. Pemberlakuan clinical pathway tidak memperbaiki outcome mortalitas, meskipun proporsi mortalitas menurun, 14,5\% sebelum pemberlakuan dan $17,8 \%$ setelah pemberlakuan. Clinical pathway secara signifikan memperbaiki proses pelayanan stroke pada esesmen menelan $(p=0,00)$, esesmen rehabilitasi $(p=0,00)$ dan edukasi saat pasien pulang $(p=0,001)$. Jenis stroke, kondisi kesadaran saat pasien masuk RS, adanya faktor risiko DM dan AF meningkatkan risiko mortalitas pasien stroke, sedangkan pelaksanaan esesmen menelan sesegera mungkin menurunkan risiko mortalitas.

Kesimpulan: Pemberlakuan clinical pathway pada pelayanan stroke memperbaiki proses pelayanan meskipun dampaknya terhadap outcome mortalitas tidak berpengaruh.
\end{abstract}

Kata Kunci: Clinical pathway, manajemen mutu, kualitas pelayanan stroke, outcome stroke, mortalitas. 


\title{
IMPACT OF CLINICAL PATHWAY IMPLEMENTATION ON QUALITY OF STROKE CARE IN BETHESDA HOSPITAL YOGYAKARTA
}

\author{
Tiara Kusumaningtyas ${ }^{1}$, Adi Utarini ${ }^{1}$, Rizaldy Taslim Pinzon ${ }^{2}$ \\ ${ }^{1}$ Public Health Department of Medical Faculty of Gadjah Mada University \\ ${ }^{2}$ Medical Faculty of Duta Wacana Christian University
}

Correspondence: tiara_blue_2@yahoo.com

\begin{abstract}
Background: Stroke is one of the major health problems worldwide. A good clinical management system is needed to improve the quality of stroke care. Clinical pathway has tremendous appeal as an integrated approach to improve quality of stroke care by reducing unnecessary variation in process and outcome. However the evidences of the impact of clinical pathway on the quality of stroke care remain questionable.

Purpose: To evaluate whether clinical pathway could improve the quality of stroke care by using processes and outcome performance indicators.

Method: This study uses before-after test without control group quasiexperimental method. The subjects are ischemic and hemorrhagic stroke patients admitted to the Stroke Unit in Bethesda Hospital. A total of 844 patients were managed on the clinical pathway compared to patients who were managed with standard care. Indicators of performances were compared (historical comparison) between the two groups of patient. Restriction and matching of study subjects in both groups ensured thus the patients selected were comparable in terms of severity of illness.

Result: The results showed that the patients on the clinical pathway and the comparison group were similar with respect to demographic variables (except sex), prevalence of risk factors and facial muscle defisit symptom. Following pathway implementation, there was no statistically significant difference on the impact of clinical pathway on stroke mortality outcome. In hospital mortality was 14,5\% prior to the pathway and 17,8\% after the pathway. The implementation of stroke care pathway is able to significantly improve some care processes; increases in the rates of swallow assessment $(p=0.00)$, rehabilitation assessment $(p=0,00)$ and education at discharge $(p=0,001)$. There is strong correlation between stroke type, level of consciousness, co morbidities of diabetes mellitus and atrial fibrillation and initial swallowing assessment with mortality.

Conclusion: Stroke care pathway appeared to improve the process of care, although it has no benefit for mortality outcome.
\end{abstract}

Keywords: Clinical pathway, continuous quality improvement, quality of stroke care, stroke outcome, mortality. 


\section{LATAR BELAKANG}

Stroke masih menjadi salah satu masalah utama kesehatan, bukan hanya di Indonesia namun di dunia. ${ }^{1,2}$ Stroke menjadi penyebab kematian nomor dua di seluruh dunia setelah penyakit jantung iskemik. ${ }^{3}$ Data Kementrian Kesehatan RI menunjukkan bahwa stroke adalah penyebab kematian nomor satu pada pasien yang dirawat di rumah sakit, delapan per seribu orang di Indonesia terkena stroke dan setiap tujuh orang yang meninggal di Indonesia dua diantaranya karena stroke. ${ }^{4}$ Meski-pun sistem diagnosis dan pelayanan stroke telah meningkat namun angka mortalitas akibat stroke masih tinggi.

Pada sejumlah penelitian mengenai kejadian stroke, angka kejadian stroke yang terbesar adalah stroke iskemik dengan presentase sebesar 67,3-80,5\%.5,6 Demikian juga yang terjadi di Indonesia, insiden stroke iskemik menduduki peringkat tertiggi dibandingkan dengan stroke tipe lainnya. Meskipun demikian stroke perdarahan mempunyai tingkat keparahan yang lebih buruk dibandingkan dengan stroke iskemik. Angka kematian yang diakibatkan oleh stroke perdarahan lebih besar dibandingkan stroke iskemik. ${ }^{7} \mathrm{Hal}$ ini menjadikan kedua jenis stroke, baik stroke iskemik maupun stroke perdarahan menjadi penting untuk diteliti.

Berbagai penelitian telah dilakukan sehubungan dengan terapi dan manajemen klinis dalam pelayanan pasien stroke akut. Namun penelitian-penelitian tersebut membuktikan bahwa sistem pelayanan stroke yang ada masih sangat bervariasi, baik dalam hal terapi maupun sistem organisasi pelayanan dan outcome..$^{8,9,10,11}$

Proses pelayanan menjadi salah satu faktor penentu outcome. ${ }^{11}$ Diperlukan adanya pelayanan stroke yang lebih terorganisir untuk mempersempit variasi proses. Dengan adanya perbaikan proses pelayanan stroke diharapkan dapat menunjang outcome kualitas pelayanan stroke yang lebih baik. Salah satu terobosan manajemen klinis yang digunakan adalah dengan pemberlakuan clinical pathway. ${ }^{13}$

Clinical pathway terbukti menunjang mutu pelayanan meskipun efektivitasnya terhadap outcome masih belum menunjukan bukti yang jelas. Masih terdapat per-debatan mengenai efektivitas clinical pathway terhadap outcome pasien stroke. 13,15,16 Mortalitas adalah outcome yang signifikan me-representasikan kualitas pelayanan stroke. ${ }^{16}$

RS Bethesda telah menerapkan clinical pathway sejak tahun 2009 di unit perawatan stroke yang menjadi salah satu pelayanan unggulannya. Oleh karenanya, dampak clinical pathway terhadap proses dan outcome pelayanan pasien stroke yang dirawat di RS Bethesda Yogyakarta menarik untuk dikaji dengan menggunakan indikator proses dan outcome.

\section{DESAIN PENELITIAN}

Desain penelitian ini adalah kuasi eksperimental dengan metode pre-test and post-test without control group, yaitu mengambil dua kelompok subyek yang berbeda dalam populasi. Populasi penelitian adalah pasien stroke iskemik dan perdarahan yang dirawat di RS Bethesda Yogyakarta. Kelompok kasus adalah kelompok pasien yang ditatalaksana dengan clinical pathway terbaru (tahun 2012), sedangkan kelompok kontrol adalah kelompok pasien sebelum clinical pathway diberlakukan (tahun 2008). Kriteria inklusi dan eksklusi ditetapkan untuk memilik subyek penelitian.

Jumlah sampel yang ditetapkan dalam penelitian ini adalah 422 
untuk menilai outcome mortalitas dan 64 sampel untuk mengukur proses pelayanan stroke. Sampel diambil secara konsekutif berdasarkan waktu, prospektif untuk kelompok kasus dan retrospektif untuk kelompok kontrol. Pada sampel proses, matching individual dilakukan dengan tujuan penyeimbangan karakteristik klinis subyek.

Penelitian ini menggunakan data sekunder rekam medis. Terdapat dua buah instrumen yang digunakan, satu instrumen untuk masing-masing kasus stroke. Instrumen penelitian dibuat berdasarkan telaah pustaka berbagai indikator mutu pelayanan stroke di rumah sakit, yaitu: Australian Clinical Indicator Report, Core Performance Indikator, Performance Assessment Tool for Quality
Improvement in Hospitals dan Inpatient Quality Indicatorsdan Joint Comission International 2011. $16,17,18,19,20$

Analisis data terhadap masing-masing hubungan variabel independent dan confounding terhadap variabel dependent mortalitas $(\mathrm{n}=844)$ dan proses $(n=128)$ akan diuji dengan uji chisquare dan kemudian dapat ditentukan RR (Relative Risk). Analisis regresi logistik selanjutnya akan digunakan untuk menjelaskan hubungan antara variabel potensial terhadap outcome mortalitas.

\section{HASIL PENELITIAN}

Subyek penelitian ini terdiri dari stroke iskemik dan stroke perdarahan yang masing-masing memiliki proporsi yang sama. Adapun karakteristik subyek dijelaskan pada Tabel 1 berikut:

Tabel 1. Karakteristik Subyek Penelitian

\begin{tabular}{|c|c|c|c|c|}
\hline Karakteristik & Pathway & Non Pathway & Total & p-Value \\
\hline \multicolumn{5}{|l|}{ Jenis Stroke } \\
\hline Iskemik & $211(50,0 \%)$ & $211(50,0 \%)$ & $422(50,0 \%)$ & 1.000 \\
\hline Perdarahan & $211(50,0 \%)$ & $211(50,0 \%)$ & $422(50,0 \%)$ & \\
\hline \multicolumn{5}{|l|}{ Jenis Perdarahan } \\
\hline Subarachnoid & $10(4,7 \%)$ & $11(5,2 \%)$ & $21(5,0 \%)$ & 0,823 \\
\hline Intracerebral & $201(95,3 \%)$ & $200(94,8 \%)$ & $401(95 \%)$ & \\
\hline \multicolumn{5}{|l|}{ Unit Stroke } \\
\hline $\mathrm{Ya}$ & $197(46,7 \%)$ & $175(41,5 \%)$ & $372(44,1 \%)$ & 0,127 \\
\hline Tidak & $225(53,3 \%)$ & $247(58,5 \%)$ & $472(55,9 \%)$ & \\
\hline \multicolumn{5}{|l|}{ Jenis Kelamin } \\
\hline Laki-laki & $222(52,6 \%)$ & 257 (60,9\%) & $479(56,8 \%)$ & 0,015 \\
\hline Perempuan & $200(47,4 \%)$ & $165(39,1 \%)$ & $365(43,2 \%)$ & \\
\hline \multicolumn{5}{|l|}{ Umur } \\
\hline$<40$ tahun & $13(3,1 \%)$ & $21(5,0 \%)$ & $34(4,0 \%)$ & 0,305 \\
\hline 41-50 tahun & $66(15,6 \%)$ & $69(16,4 \%)$ & $135(16,0 \%)$ & \\
\hline $51-60$ tahun & $101(23,9 \%)$ & $117(27,7 \%)$ & $218(25,8 \%)$ & \\
\hline 61-70 tahun & $129(30,6 \%)$ & $118(28,0 \%)$ & $247(29,3 \%)$ & \\
\hline$>70$ tahun & $113(26,8 \%)$ & $97(23,0 \%)$ & $210(24,9 \%)$ & \\
\hline \multicolumn{5}{|l|}{ Serangan } \\
\hline Pertama & $309(73,2 \%)$ & $286(67,8 \%)$ & $595(70,5 \%)$ & 0,083 \\
\hline Ulangan & $113(26,8 \%)$ & $136(32,2 \%)$ & $249(29,5 \%)$ & \\
\hline Onset & $59(14 \%)$ & $70(16,6 \%)$ & $129(15,3 \%)$ & 0,075 \\
\hline$<3$ & $78(18,5 \%)$ & $72(17,1 \%)$ & $150(17,8 \%)$ & \\
\hline $3-6$ & $69(16,4 \%)$ & $94(22,4 \%)$ & $163(19,3 \%)$ & \\
\hline
\end{tabular}




\begin{tabular}{|c|c|c|c|c|}
\hline Karakteristik & Pathway & Non Pathway & Total & p-Value \\
\hline $6-12$ & $58(13,7 \%)$ & $41(9,7 \%)$ & $99(11,7 \%)$ & \\
\hline $12-24$ & $158(37,4 \%)$ & $145(34,4 \%)$ & $303(35,9 \%)$ & \\
\hline$>24$ & & & & \\
\hline \multicolumn{5}{|l|}{ GCS } \\
\hline $13-15$ & $323(76,5 \%)$ & $335(79,4 \%)$ & 658 (78,0\%) & \multirow[t]{3}{*}{0,195} \\
\hline $8-12$ & $92(21,8 \%)$ & $75(17,8 \%)$ & $167(19,8 \%)$ & \\
\hline$<8$ & $7(1,7 \%)$ & $12(2,8 \%)$ & $19(2,3 \%)$ & \\
\hline \multicolumn{5}{|l|}{ Gejala: } \\
\hline Penurunan Kesada & & & & \multirow{3}{*}{0,194} \\
\hline Ya & $107(25,4 \%)$ & $91(21,6 \%)$ & $198(23,5 \%)$ & \\
\hline Tidak & $315(74,6 \%)$ & $331(78,4 \%)$ & $646(76,5 \%)$ & \\
\hline \multicolumn{5}{|l|}{ BerbicaraPelo } \\
\hline /Disartria & & & & \\
\hline $\mathrm{Ya}$ & 83 (19,7\%) & $62(14,7 \%)$ & 145 (17,2\%) & \multirow{2}{*}{0,055} \\
\hline Tidak & $339(80,3 \%)$ & $360(85,3 \%)$ & $699(82,8 \%)$ & \\
\hline \multicolumn{5}{|l|}{ Hemiparese } \\
\hline $\mathrm{Ya}$ & $245(58,1 \%)$ & 227 (53,8\%) & $472(55,9 \%)$ & \multirow[t]{2}{*}{0,212} \\
\hline Tidak & 177 (41,9\%) & $195(46,2 \%)$ & $372(44,1 \%)$ & \\
\hline \multicolumn{5}{|l|}{ Afasia } \\
\hline Ya & $71(16,8 \%$ & 57 (13,5\%) & $128(15,2 \%)$ & \multirow[t]{2}{*}{0,179} \\
\hline Tidak & $351(83,2 \%)$ & $365(86,5 \%)$ & $716(84,8 \%)$ & \\
\hline \multicolumn{5}{|l|}{ Wajah perot } \\
\hline Ya & $9(2,1 \%)$ & $0(0 \%)$ & $9(1,1 \%)$ & \multirow[t]{2}{*}{0,004} \\
\hline Tidak & 413 (97,9\%) & 422 (100\%) & 835 (98,9\%) & \\
\hline \multicolumn{5}{|l|}{ LOS } \\
\hline Iskemik & 7,692 & 8,076 & Meand dif. & \multirow[t]{3}{*}{0,046} \\
\hline Perdarahan & 11,521 & 13,493 & & \\
\hline Gabungan & 9,607 & 10,784 & $-1,18$ & \\
\hline
\end{tabular}

Berdasarkan dari karakteristik yang dipaparkan pada tabel 1 dapat disimpulkan bahwa pada penelitian ini terdapat perbedaan signifikan secara statistik pada karakteristik jenis kelamin, gejala wajah perot dan lama hari perawatan.

\section{Perbaikan Indikator Proses Pelayanan Stroke}

Dari 211 sampel pada masingmasing kelompok setelah itu dipilih 32 subyek dari masing-masing kelompok pathway dan non pathway. Adapun hasil rekapitulasi indikator proses dijelaskan dalam Tabel 2 berikut:

Tabel 2. Perbandingan Proses Sebelum dan Sesudah Pemberlakukan Clinical Pathway

\begin{tabular}{lcccc}
\hline \multicolumn{1}{c}{ Proses } & Pathway & Non Pathway & Total & p-Value \\
\hline CT-Scan & $64(100 \%)$ & $64(100 \%)$ & $128(100 \%)$ & 1,000 \\
$\quad$ Ya & $0(0 \%)$ & $0(0 \%)$ & $0(0 \%)$ & \\
$\quad$ Tidak & & & & \\
Essesmen Menelan & $54(84,4 \%)$ & $0(0 \%)$ & $54(42,2 \%)$ & 0,000 \\
$\quad$ Ya & $10(15,6 \%)$ & $64(100 \%)$ & $74(57,8 \%)$ & \\
$\quad$ Tidak & & & & \\
Essesmen Rehabilitasi & & & \\
$\quad$ Ya & $55(85,9 \%)$ & $18(28,1 \%)$ & $73(57,0 \%)$ & 0,000 \\
& & & &
\end{tabular}




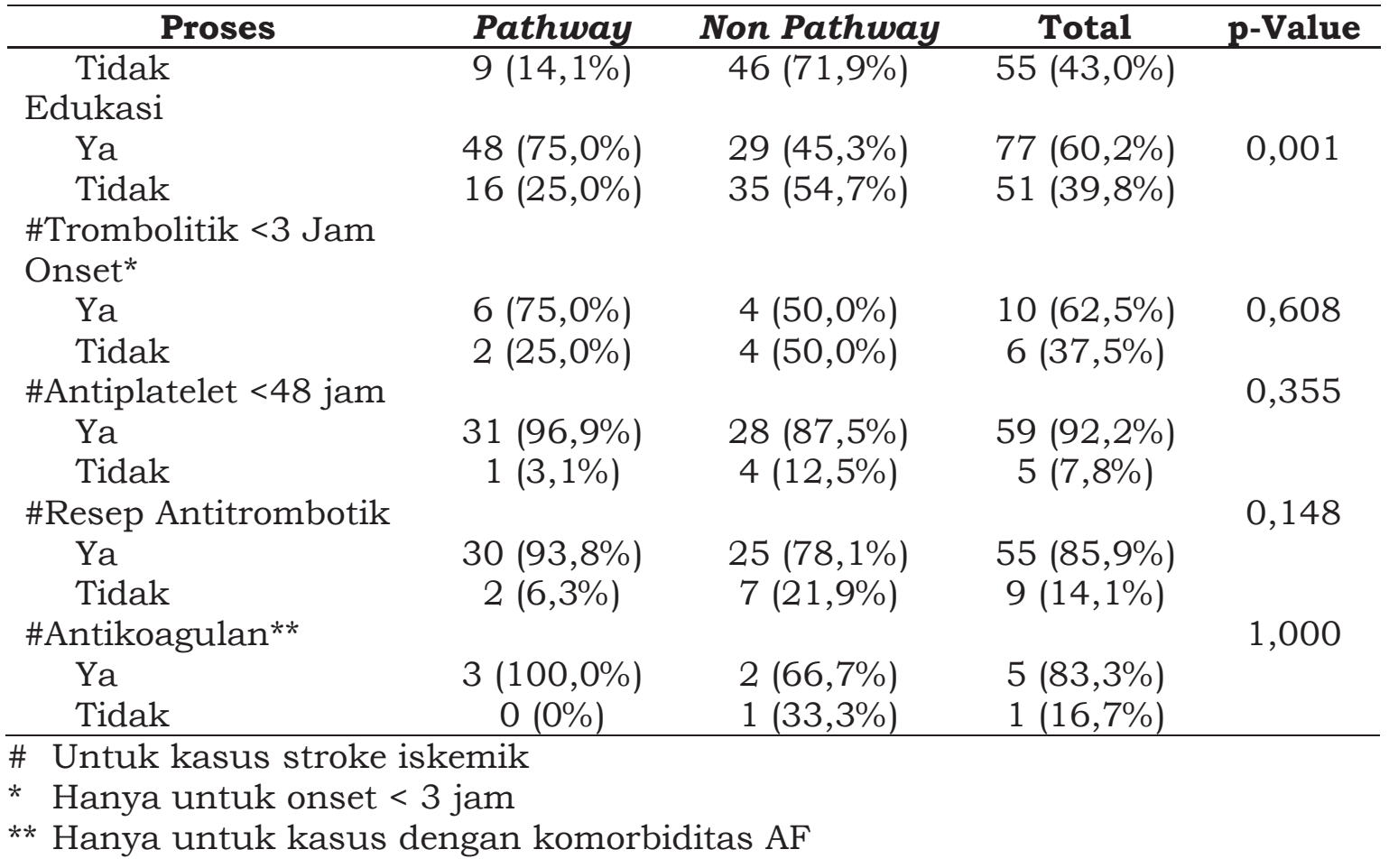

Terdapat perbedaan dalam menjalankan proses pelayanan setelah pemberlakuan clinical pathway dibandingkan dengan sebelum diberlakukan clinical pathway. Perbedaan tersebut terdapat pada esesmen menelan, esemen rehabilitasi dan edukasi $(\mathrm{p}<0,05)$.

\section{Outcome Mortalitas}

Clinical pathway selain bertujuan untuk memperbaiki proses diharapkan dapat memperbaiki outcome pelayanan. Analisis bivariat hubungan clinical pathway dan karakteristik pasien terhadap outcome mortalitas dijelaskan dalam Tabel 3 seperti berikut:

Tabel 3. Analisis Bivariat terhadap Outcome Mortalitas

\begin{tabular}{|c|c|c|c|c|c|}
\hline Confounding & $\begin{array}{c}\text { Mortalitas } \\
\text { Ya }\end{array}$ & $\begin{array}{l}\text { Total } \\
\text { Tidak }\end{array}$ & p-value & $\mathbf{R} \mathbf{R}$ & Confounding \\
\hline \multicolumn{6}{|l|}{ Clinical Pathway } \\
\hline $\mathrm{Ya}$ & $61(14,5 \%)$ & $\begin{array}{c}361 \\
(85,5 \%)\end{array}$ & $\begin{array}{c}422 \\
(100,0 \%)\end{array}$ & 0,224 & $\begin{array}{c}0,813 \\
(0,597-1,109)\end{array}$ \\
\hline Tidak & $75(17,8 \%)$ & $\begin{array}{c}347 \\
(82,2 \%)\end{array}$ & $\begin{array}{c}422 \\
(100,0 \%)\end{array}$ & & \\
\hline \multicolumn{6}{|l|}{ Jenis Stroke } \\
\hline Perdarahan & $\begin{array}{c}104 \\
(76,5 \%)\end{array}$ & $\begin{array}{c}318 \\
(44,9 \%)\end{array}$ & $\begin{array}{c}422 \\
(50,0 \%)\end{array}$ & 0,000 & $\begin{array}{c}3,250 \\
(2,239-4,717)\end{array}$ \\
\hline Iskemik & $32(23,5 \%)$ & $\begin{array}{c}390 \\
(55,1 \%)\end{array}$ & $\begin{array}{c}422 \\
(50,0 \%)\end{array}$ & & \\
\hline \multicolumn{6}{|l|}{ Jenis Perdarahan } \\
\hline Subarachnoid & $8(7,7 \%)$ & $\begin{array}{c}13 \\
(4,1 \%)\end{array}$ & $\begin{array}{c}21 \\
(5,0 \%)\end{array}$ & 0,142 & $\begin{array}{c}1,591 \\
(0,898-2,821)\end{array}$ \\
\hline Intracerebral & $96(92,3 \%)$ & $\begin{array}{c}305 \\
(95,9 \%)\end{array}$ & $\begin{array}{c}401 \\
(95,0 \%)\end{array}$ & & \\
\hline
\end{tabular}




\begin{tabular}{|c|c|c|c|c|c|}
\hline Confounding & $\begin{array}{c}\text { Mortalitas } \\
\text { Ya } \\
\end{array}$ & \begin{tabular}{|l|} 
Total \\
Tidak \\
\end{tabular} & p-value & $\mathbf{R} \mathbf{R}$ & Confounding \\
\hline $\mathrm{Ya}$ & $61(44,9 \%)$ & $\begin{array}{c}311 \\
(45,1 \%)\end{array}$ & $\begin{array}{c}372 \\
(44,0 \%)\end{array}$ & 0,853 & $\begin{array}{c}0,991 \\
(0,727-1,350)\end{array}$ \\
\hline Tidak & $75(55,1 \%)$ & $\begin{array}{c}396 \\
(54,9 \%)\end{array}$ & $\begin{array}{c}472 \\
(56,0 \%)\end{array}$ & & \\
\hline Jenis Kelamin & & & & 0,272 & \\
\hline Laki-laki & $\begin{array}{l}83(61,0 \%) \\
53(39,0 \%)\end{array}$ & $\begin{array}{c}396 \\
(55,9 \%)\end{array}$ & $\begin{array}{c}479 \\
(56,8 \%)\end{array}$ & & $\begin{array}{c}1,193 \\
(0,870-1,638)\end{array}$ \\
\hline Perempuan & & $\begin{array}{c}312 \\
(44,1 \%)\end{array}$ & $\begin{array}{c}365 \\
(43,2 \%)\end{array}$ & & \\
\hline \multicolumn{6}{|l|}{ Umur } \\
\hline$<40$ tahun & $1(0,7 \%)$ & $\begin{array}{c}33 \\
(4,7 \%)\end{array}$ & $\begin{array}{c}34 \\
(4,0 \%)\end{array}$ & 0,141 & - \\
\hline 41-50 tahun & $18(13,2 \%)$ & $\begin{array}{c}117 \\
(16,5 \%)\end{array}$ & $\begin{array}{c}135 \\
(16,0 \%)\end{array}$ & & \\
\hline 51-60 tahun & $34(25,0 \%)$ & $\begin{array}{c}184 \\
(26,0 \%)\end{array}$ & $\begin{array}{c}218 \\
(25,8 \%)\end{array}$ & & \\
\hline 61-70 tahun & 47 (34,6\%) & $\begin{array}{c}200 \\
(28,2 \%)\end{array}$ & $\begin{array}{c}247 \\
(29,3 \%)\end{array}$ & & \\
\hline$>70$ tahun & $36(26,5 \%)$ & $\begin{array}{c}174 \\
(24,6 \%)\end{array}$ & $\begin{array}{c}210 \\
(24,9 \%)\end{array}$ & & \\
\hline \multicolumn{6}{|l|}{ Serangan } \\
\hline Pertama & $90(66,2 \%)$ & $\begin{array}{c}505 \\
(71,3 \%)\end{array}$ & $\begin{array}{c}595 \\
(70,5 \%)\end{array}$ & 0,228 & $\begin{array}{c}0,819 \\
(0,593-1,131)\end{array}$ \\
\hline Ulangan & $46(33,8 \%)$ & $\begin{array}{c}203 \\
(28,7 \%)\end{array}$ & $\begin{array}{c}249 \\
(29,5 \%)\end{array}$ & & \\
\hline Onset & & & & & - \\
\hline$<3$ & $13(9,6 \%)$ & $\begin{array}{c}116 \\
(16,4 \%)\end{array}$ & $\begin{array}{c}129 \\
(15,3 \%)\end{array}$ & 0,233 & \\
\hline $3-6$ & $26(19,1 \%)$ & $\begin{array}{c}124 \\
(17,5 \%)\end{array}$ & $\begin{array}{c}150 \\
(17,8 \%)\end{array}$ & & \\
\hline $6-12$ & $26(19,1 \%)$ & $\begin{array}{c}137 \\
(19,4 \%)\end{array}$ & $\begin{array}{c}163 \\
(19,3 \%)\end{array}$ & & \\
\hline $12-24$ & $21(15,4 \%)$ & $\begin{array}{c}78 \\
(11,0 \%)\end{array}$ & $\begin{array}{c}99 \\
(11,7 \%)\end{array}$ & & \\
\hline$>24$ & $50(36,8 \%)$ & $\begin{array}{c}253 \\
(35,7 \%)\end{array}$ & $\begin{array}{c}303 \\
(35,9 \%)\end{array}$ & & \\
\hline \multicolumn{6}{|l|}{ GCS } \\
\hline$<8$ & $19(14,0 \%)$ & $\begin{array}{c}0 \\
(0,0 \%)\end{array}$ & $\begin{array}{c}19 \\
(2,3 \%)\end{array}$ & 0,000 & - \\
\hline $9-12$ & 76 (55,9\%) & $\begin{array}{c}91 \\
(12,9 \%)\end{array}$ & $\begin{array}{c}167 \\
(19,8 \%)\end{array}$ & & \\
\hline $13-15$ & $41(30,1 \%)$ & $\begin{array}{c}617 \\
(87,1 \%)\end{array}$ & $\begin{array}{c}658 \\
(78,0 \%)\end{array}$ & & \\
\hline \multicolumn{6}{|l|}{$\begin{array}{l}\text { Penurunan } \\
\text { kesadaran }\end{array}$} \\
\hline $\mathrm{Ya}$ & 97 (71,3\%) & $\begin{array}{c}101 \\
(14,3 \%)\end{array}$ & $\begin{array}{c}198 \\
(23,5 \%)\end{array}$ & 0,000 & $\begin{array}{c}8,115 \\
(5,800-\end{array}$ \\
\hline Tidak & $39(28,7 \%)$ & & & & $11,353)$ \\
\hline
\end{tabular}




\begin{tabular}{|c|c|c|c|c|c|}
\hline Confounding & $\begin{array}{c}\text { Mortalitas } \\
\text { Ya }\end{array}$ & $\begin{array}{c}\text { Total } \\
\text { Tidak }\end{array}$ & p-value & $\mathbf{R} \mathbf{R}$ & Confounding \\
\hline & & $\begin{array}{c}607 \\
(85,7 \%)\end{array}$ & $\begin{array}{c}646 \\
(76,5 \%)\end{array}$ & & \\
\hline \multicolumn{6}{|l|}{ Bicara pelo } \\
\hline $\mathrm{Ya}$ & $\begin{array}{c}20(14,7 \%) \\
116\end{array}$ & $\begin{array}{c}125 \\
(17,7 \%)\end{array}$ & $\begin{array}{c}145 \\
(17,2 \%)\end{array}$ & 0,404 & $\begin{array}{c}0,831 \\
(0,536-1,290)\end{array}$ \\
\hline Tidak & $(85,3 \%)$ & $\begin{array}{c}583 \\
(82,3 \%)\end{array}$ & $\begin{array}{c}699 \\
(82,8 \%)\end{array}$ & & \\
\hline \multicolumn{6}{|l|}{ Afasia } \\
\hline $\mathrm{Ya}$ & $25(18,4 \%)$ & $\begin{array}{c}103 \\
(14,55)\end{array}$ & $\begin{array}{c}128 \\
(15,2 \%)\end{array}$ & 0,254 & $\begin{array}{c}1,260 \\
(0,852-1,863)\end{array}$ \\
\hline Tidak & $\begin{array}{c}111 \\
(81,6 \%)\end{array}$ & $\begin{array}{c}605 \\
(85,5 \%)\end{array}$ & $\begin{array}{c}716 \\
(84,8 \%)\end{array}$ & & \\
\hline \multicolumn{6}{|l|}{ Wajah perot } \\
\hline $\mathrm{Ya}$ & $0(0,0 \%)$ & $\begin{array}{c}9 \\
(1,3 \%)\end{array}$ & $9(1,1 \%)$ & 0,369 & $\begin{array}{c}1,195 \\
(1,159-1.231)\end{array}$ \\
\hline Tidak & $\begin{array}{c}136 \\
(100,0 \%)\end{array}$ & $\begin{array}{c}699 \\
(98,7 \%)\end{array}$ & $\begin{array}{c}835 \\
(98,9 \%)\end{array}$ & & \\
\hline \multicolumn{6}{|l|}{ Hemiparesis } \\
\hline $\mathrm{Ya}$ & $79(58,1 \%)$ & $\begin{array}{c}393 \\
(55,5 \%)\end{array}$ & $\begin{array}{c}472 \\
(55,9 \%)\end{array}$ & 0,579 & $\begin{array}{c}1,092 \\
(0,799-1,493)\end{array}$ \\
\hline Tidak & 57 (41,9\%) & $\begin{array}{c}315 \\
(44,5 \%)\end{array}$ & $\begin{array}{c}372 \\
(44,1 \%)\end{array}$ & & \\
\hline \multicolumn{6}{|l|}{ Komorbiditas } \\
\hline Tidak ada & $18(13,2 \%)$ & $\begin{array}{c}149 \\
(21,0 \%)\end{array}$ & $\begin{array}{c}167 \\
(19,8 \%)\end{array}$ & 0,036 & $\begin{array}{c}1,617 \\
(1,015-2,577)\end{array}$ \\
\hline Ada & $\begin{array}{c}118 \\
(86,8 \%)\end{array}$ & $\begin{array}{c}559 \\
(79,0 \%)\end{array}$ & $\begin{array}{c}677 \\
(80,2 \%)\end{array}$ & & \\
\hline \multicolumn{6}{|l|}{ Dislipidemia } \\
\hline $\mathrm{Ya}$ & $46(33,8 \%)$ & $\begin{array}{c}300 \\
(42,4 \%)\end{array}$ & $\begin{array}{c}346 \\
(41,0 \%)\end{array}$ & 0,063 & $\begin{array}{c}0,736 \\
(0,530-1,021)\end{array}$ \\
\hline Tidak & $90(66,2 \%)$ & $\begin{array}{c}408 \\
(57,6 \%)\end{array}$ & $\begin{array}{c}498 \\
(59,0 \%)\end{array}$ & & \\
\hline \multicolumn{6}{|l|}{ Hipertensi } \\
\hline $\mathrm{Ya}$ & $46(33,8 \%)$ & $\begin{array}{c}308 \\
(43,5 \%)\end{array}$ & $\begin{array}{c}354 \\
(41,9 \%)\end{array}$ & 0.036 & $\begin{array}{c}0,707 \\
(0,510-0,982)\end{array}$ \\
\hline Tidak & $90(66,2 \%)$ & $\begin{array}{c}400 \\
(56,5 \%)\end{array}$ & $\begin{array}{c}490 \\
(58,1 \%)\end{array}$ & & \\
\hline \multicolumn{6}{|l|}{$\begin{array}{l}\text { Diabetes Melitus } \\
\text { (DM) }\end{array}$} \\
\hline Ya & $22(16,2 \%)$ & $\begin{array}{c}73 \\
(10,3 \%)\end{array}$ & $\begin{array}{c}95 \\
(11,5 \%)\end{array}$ & 0,047 & $\begin{array}{c}1,522 \\
(1,016-2,278)\end{array}$ \\
\hline Tidak & $\begin{array}{c}114 \\
(83,8 \%)\end{array}$ & $\begin{array}{c}635 \\
(89,7 \%)\end{array}$ & $\begin{array}{c}749 \\
(88,7 \%)\end{array}$ & & \\
\hline \multicolumn{6}{|l|}{ Atrial Fibrilasi (AF) } \\
\hline $\mathrm{Ya}$ & $10(4,7 \%)$ & $\begin{array}{c}9 \\
(1,3 \%)\end{array}$ & $\begin{array}{c}19 \\
(2,3 \%)\end{array}$ & 0,000 & $\begin{array}{c}3,446 \\
(2,185-5,436)\end{array}$ \\
\hline Tidak & $\begin{array}{c}126 \\
(92,6 \%)\end{array}$ & $\begin{array}{c}699 \\
(98,7 \%)\end{array}$ & $\begin{array}{c}825 \\
(97,7 \%)\end{array}$ & & \\
\hline
\end{tabular}




\begin{tabular}{|c|c|c|c|c|c|}
\hline Confounding & $\frac{\text { Mortalitas }}{\text { Ya }}$ & $\begin{array}{r}\text { Total } \\
\text { Tidak }\end{array}$ & p-value & $\mathbf{R} \mathbf{R}$ & Confounding \\
\hline $\begin{array}{l}\text { Ischemic Heart } \\
\text { Disease }\end{array}$ & & & & & \\
\hline $\begin{array}{l}\text { Ya } \\
\text { Tidak }\end{array}$ & $\begin{array}{c}14(10,3 \%) \\
122 \\
(89,7 \%)\end{array}$ & $\begin{array}{c}57 \\
(8,1 \%) \\
651 \\
(91,9 \%) \\
\end{array}$ & $\begin{array}{c}71 \\
(8,4 \%) \\
773 \\
(91,6 \%) \\
\end{array}$ & 0,388 & $\begin{array}{c}1,249 \\
(0,760-2,053)\end{array}$ \\
\hline
\end{tabular}

Berdasarkan hasil uji statistik Tabel 3 menunjukkan bahwa pemberlakuan clinical pathway tidak memperbaiki outcome mortalitas pelayanan stroke di RS Bethesda $(\mathrm{p}>0,05)$. Dapat kita simpulkan bahwa jenis stroke, gejala penurunan kesadaran, GCS, adanya faktor risiko dan komorbiditas HT, DM serta AF berhubungan dengan outcome mortalitas pasien $(\mathrm{p}<0,05)$. Untuk mengetahui hubungan tersebut peneliti melakukan analisis multivariat regresi logistik terhadap variabel potensial dengan hasil sebagai berikut:

Tabel 4. Analisis Multivariat Faktor Risiko Outcome Mortalitas

\begin{tabular}{lccccc}
\hline \multirow{2}{*}{ Variabel Potensial } & \multirow{2}{*}{ B } & Sig. & RR & 95,0\% C.I.for EXP(B) \\
\cline { 5 - 6 } & & & adjusted & Lower & Upper \\
\hline Stroke Perdarahan &, 696 &, 012 & 2,007 & 1,169 & 3,446 \\
GCS &, 568 &, 035 & 1,764 & 1,039 & 2,996 \\
Penurunan kesadaran & 1,901 &, 000 & 6,691 & 4,379 & 10,223 \\
Tanfa faktor risiko & $-1,164$ &, 000 &, 312 &, 179 &, 545 \\
Komorbiditas DM &, 718 &, 026 & 2,051 & 1,091 & 3,855 \\
Komorbiditas AF & 1,280 &, 026 & 3,595 & 1,166 & 11,082 \\
Komorbiditas HT &, 124 &, 599 & 1,132 &, 713 & 1,798 \\
Esesmen menelan & $-2,682$ &, 010 &, 068 &, 009 &, 534 \\
Resep antitrombotik & $-22,456$ &, 997 &, 000 &, 000 & - \\
\hline
\end{tabular}

Hasil regresi logistik menunjukkan bahwa jenis stroke perdarahan, GCS $<8$, gejala penurunan kesadaran saat admisi serta adanya komorbiditas AF dan DM meningkatkan risiko mortalitas pasien stroke, sedangkan assesmen menelan sesegera mungkin menurunkan risiko mortalitas.

\section{PEMBAHASAN}

Clinical pathway bertujuan untuk memperbaiki proses penatalaksanaan stroke agar lebih efektif dan efisien.1,13,22,23 Dengan perbaikan indikator proses diharapkan adanya perbaikan outcome. Pada penelitian ini pemberlakuan clinical pathway terbukti memperbaiki pencapaian indikator proses pe- layanan stroke yang meliputi penilaian fungsi menelan $(0 \%$ sebelum pemberlakuan pathway dan $100 \%$ setelah pemberlakuan), esesmen rehabilitasi $(54,7 \%$ vs $85,9 \%$ ) dan pemberian edukasi pada pasien maupun keluarga saat pasien pulang $(45,3 \%$ vs $75 \%)$. Berdasarkan observasi data rekam medis selama proses pengambilan data, peneliti berpendapat bahwa perbaikan pencapaian indikator proses yang terjadi erat kaitannya dengan fungsi clinical pathway sebagai reminder. Sejak pemberlakuan clinical pathway kelengkapan dokumentasi pasien pun meningkat. Hal ini menunjukkan adanya kemungkinan bahwa rendahnya pencapaian indikator proses sebelum clinical pathway 
diberlakukan bukan berarti prosesproses tersebut tidak benar-benar dilaksanakan. Kelengkapan dokumentasi menjadi salah satu alasannya. Selaras dengan beberapa penelitian sebelumnya, bahwa pathway mampu memperbaiki kelengkapan dokumentasi pasien. $15,24,25$

Perbaikan proses yang terjadi setelah pemberlakuan clinical pathway di RS Bethesda Yogyakarta tidak diikuti dengan perbaikan outcome mortalitas ( $>0,05 \%$; CI:95\%). Hal ini disebabkan bahwa mortalitas sebagai salah satu indikator outcome pelayanan stroke tidak hanya dipengaruhi oleh input dan proses pelayanan. Mortalitas pada stroke erat hubungannya dengan kondisi klinis pasien. Dari analisis multivariat terdapat beberapa faktor lain diluar faktor proses dan clinical pathway, yang meningkatkan risiko outcome mortalitas. Faktor-faktor tersebut adalah jenis stroke perdarahan $(\mathrm{RR}=2,00 ; \quad 95 \% \mathrm{CI} ; \quad 2,139-5,538)$, penurunan kesadaran saat admisi $(\mathrm{RR}=6,69 ; \quad 95 \% \mathrm{CI} ; \quad 4,379-10,223)$, skor GCS < $8 \quad(\mathrm{RR}=1,76 ; 95 \% \mathrm{CI}$; 1,039-2,996), Faktor risiko atrial fibrilasi $(\mathrm{RR}=3,59 ; 95 \% \mathrm{CI}$; 1,16611,082) dan faktor risiko diabetes mellitus ( $R R=2,05 ; 95 \% \mathrm{CI} ; 3,855)$.

Kelemahan dari penelitian ini adalah peneliti hanya mengukur satu outcome dari indikator outcome pelayanan stroke. Peneliti juga tidak mengukur faktor input dalam pelayanan stroke sebelum dan setelah pemberlakuan clinical pathway. Padahal faktor input atau karakteristik demografi RS seperti profesionalisme tim pathway, ketersediaan peralatan yang memadai serta dukungan dari struktur organisasi/ manajemen RS memiliki peran penting dalam menetukan strategi terlaksananya sebuah clinical pathway.1,26,27

\section{KESIMPULAN}

Pemberlakuan clinical pathway pada pelayanan stroke di RS Bethesda memperbaiki pencapaian indikator proses pelayanan stroke yang berupa assesmen menelan, assesmen rehabilitasi dan edukasi. Pemberlakuan clinical pathway pada pelayanan stroke di RS Bethesda tidak memperbaiki outcome mortalitas. Terdapat hubungan antara proses assesmen menelan dengan perbaikan outcome mortalitas pelayanan stroke di RS Bethesda. Jenis stroke perdarahan, GCS $<8$, gejala penurunan kesadaran saat admisi serta adanya komorbiditas $\mathrm{AF}$ dan DM meningkatkan risiko mortalitas.

\section{DAFTAR PUSTAKA}

1. Panella, Marchisio S, Brambilla R, Vanhaecht K, Di Stanislao F. A cluster randomized trial to assess the effect of clinical pathway s for patients with stroke: results of the clinical pathway $s$ for effective and appropriate care study. BMC Med. [Internet]. 2012 Jan; 10:71. Available from: http://www. pubmedcentral.nih.gov/articlere nder.fcgi?artid $=3403956 \&$ tool $=p$ mcentrez\&rendertype $=$ abstract

2. Bejot $\mathrm{Y}$, Benatru I, Rouaud O, Fromont A, Besancenot JP, Moreau T, et al. Epidemiology of stroke in Europe: geographic and environmental differences. J. Neurol. Sci. [Internet]. 2007 Nov 15 [cited 2012 Aug 4];262(12):85-8. Available from: http:/ /www.ncbi.nlm.nih.gov/pu bmed/17761197

3. Donnan G a, Fisher M, Macleod M, Davis SM. Stroke. Lancet [Internet]. 2008 May 10;371(9624):1612-23. Available from: http://www.ncbi.nlm.nih. gov/pubmed/ 18468545

4. Kemenkes. 8 dari 1000 Orang di Indonesia Terkena Stroke 
[Internet]. 2011 [cited 2012 Sep 12]. Available from: http://www. depkes.go.id/index.php/berita/p ress-release/1703-8-dari-1000orang-di-indonesia-terkenastroke.html

5. Feigin VL, Lawes CMM, Bennett D a, Anderson CS. Stroke epidemiology: a review of population-based studies of incidence, prevalence, and casefatality in the late 20th century. Lancet Neurol. [Internet]. 2003 Jan;2(1):43-53. Available from: http://www.ncbi.nlm.nih.gov/pu bmed/ 12849300

6. Kirshner HS, Biller J, Callahan AS. Long-term therapy to prevent stroke. J. Am. Board Fam. Pract. [Internet]. 2005;18(6):528-40. Available from: http://www.ncbi. nlm.nih.gov/pubmed/16322415

7. Syswanda. Thesis: Faktor Risiko Keparahan Stroke di RSUP Dr.Sardjito Yogyakarta. Faculty of Medicine Gadjah Mada University; 2011. p. 9

8. Bliss J. Supporting life after stroke. Br. J. Community Nurs. [Internet]. 2011 Feb;16(2):57. Available from: http://www.ncbi. nlm.nih.gov/pubmed/21378668

9. Wolfe $\mathrm{CD}$ a, Tilling $\mathrm{K}$, Rudd a, Giroud M, Inzitari D. Variations in care and outcome in the first year after stroke: a Western and Central European perspective. J. Neurol. Neurosurg. Psychiatry [Internet]. 2004 Dec [cited 2012 Oct 22];75(12):1702-6. Available from:

http://www.pubmedcentral.nih. gov / articlerender.fcgi?artid $=173$

8847\&tool=pmcentrez\&rendertyp $\mathrm{e}=$ abstract

10. Addo J, Bhalla a., Crichton S, Rudd a. G, McKevitt C, Wolfe CD a. Provision of acute stroke care and associated factors in a multiethnic population: prospective study with the South London Stroke Register. Bmj
[Internet]. 2011 Feb 24 [cited 2012 Oct 22];342(feb24 1):d744d744. Available from: http:// www.bmj.com/cgi/doi/10.1136/ bmj.d744

11. Weir NU, Sandercock $P$ a. G, Lewis SC, Signorini DF, Warlow CP. Variations Between Countries in Outcome After Stroke in the International Stroke Trial (IST). Stroke [Internet]. 2001 Jun 1 [cited 2012 Oct 22];32(6):1370-7. Available from: http://stroke. ahajournals.org/cgi/doi/10.116 1/01.STR.32.6.1370

12. Pinzon R, Asanti L, Widyo K. Peran Clinical Pathway dalam Memperbaiki Proses Pelayanan Stroke. 2009;(2):79-83.

13. Cheah J. Development and implementation of a clinical pathway programme in an acute care general hospital in Singapore. Int. J. Qual. Health Care [Internet]. 2000 Oct;12(5):40312. Available from: http://www. ncbi.nlm.nih.gov/pubmed/1107 9220

14. Rotter T, Kinsman L, E1 J, Machotta A, Gothe H, Willis J, et al. Clinical pathways: effects on professional practice, patient outcomes, length of stay and hospital costs (Review). 2010;(7).

15. Taylor WJ, Wong A, Siegert RJ, Mcnaughton HK. Effectiveness of a clinical pathway for acute stroke care in a district general hospital: an audit. 2006;7:1-8.

16. WHO PATH. Performance Assessment Tool for Quality Improvement in Hospitals. 2009;(December): 15 .

17. The Australian Council of Healthcare Standards. Australasian Clinical Indicator Report. 2011. p. 68.

18. Group EW. Canadian Stroke Strategy Core Performance Indicator Update 2010 Developed by : 2010;(June). 
19. Agency for Healthcare Research and Quality. Guide to Inpatient Quality Indicators. California; 2004 p. 68.

20. Joint Comission International. International Hospital Inpatient Quality Measures. 2011; (January):1-6.

21. Cheah J. Clinical pathways--an evaluation of its impact on the quality of care in an acute care general hospital in Singapore. Singapore Med. J. [Internet]. 2000 Jul;41(7):335-46. Available from: http://www.ncbi.nlm.nih. gov/pubmed/11026801

22. Kwan J. Care pathways for acute stroke care and stroke rehabilitation: from theory to evidence. J. Clin. Neurosci. [Internet]. 2007 Mar [cited 2012 Sep 5];14(3):189-200. Available from: http://www.ncbi.nlm.nih. gov/pubmed/17258128

23. Cheah TS. The impact of clinical guidelines and clinical pathway $s$ on medical practice: effectiveness and medico-legal aspects. Ann.
Acad. Med. Singapore [Internet]. 1998 Jul;27(4):533-9. Available from: http://www.ncbi.nlm.nih. gov/pubmed/9791662

24. Kwan J. In-Hospital Care Pathways for Stroke: A Cochrane Systematic Review. Stroke [Internet]. 2003 Jan 30 [cited 2012 Aug 28];34(2):587-8. Available from: http://stroke. ahajournals.org/cgi/doi/10.116 1/01.STR.0000054673.28010.1 $\mathrm{B}$

25. Vanhaecht K. The impact of Clinical Pathways on the organisation of care processes. 2007.

26. Deneckere S, Euwema M, Van Herck P, Lodewijckx C, Panella M, Sermeus W, et al. Care pathways lead to better teamwork: results of a systematic review. Soc. Sci. Med. [Internet]. Elsevier Ltd; 2012 Jul [cited 2012 Jul 17];75(2):264-8. Available from: http: / /www.ncbi.nlm.nih.gov/pu bmed/22560883 